\title{
TITLE:
}

\section{Circannual rhythm in the varied carpet beetle, Anthrenus verbasci.}

\section{AUTHOR(S):}

Miyazaki, Yosuke; Nisimura, Tomoyosi; Numata, Hideharu

\section{CITATION:}

Miyazaki, Yosuke ... [et al]. Circannual rhythm in the varied carpet beetle, Anthrenus verbasci.. Progress in brain research 2012, 199: 439-456

\section{ISSUE DATE:}

2012

URL:

http://hdl.handle.net/2433/159902

\section{RIGHT:}

(c) 2012 Elsevier B.V.; この論文は出版社版でありません。引用の際には 出版社版をご確認ご利用ください。; This is not the published version. Please cite only the published version. 


\section{CHAPTER XX}

\section{Circannual rhythm in the varied carpet beetle, Anthrenus verbasci}

Yosuke Miyazaki ${ }^{\dagger}$, Tomoyosi Nisimura $\stackrel{\ddagger}{\ddagger}$ and Hideharu Numata ${ }^{\S}$,

${ }^{\dagger}$ Faculty of Clinical Education, Ashiya University, Hyogo 659-8511, Japan

College of Bioresource Sciences, Nihon University, Fujisawa 252-0880, Japan

$\S$

Graduate School of Science, Kyoto University, Kyoto 606-8502, Japan

*Corresponding author: Tel.: +81 75753 4073; Fax: +81 75753 4113; E-mail: numata@ethol.zool.kyoto-u.ac.jp. 


\begin{abstract}
Although circannual rhythms controlling different physiological processes and various aspects of behavior have been reported in numerous organisms, our understanding of the underlying biological mechanisms is still quite limited. We examined the mechanisms controlling the circannual pupation rhythm of the varied carpet beetle, Anthrenus verbasci. This rhythm is self-sustainable, exhibits temperature compensation of the periodicity, and is entrainable to environmental changes. In addition, the circannual phase response curves to a photoperiod pulse display Type 0 or Type 1 resetting, depending on the duration of the pulse. Thus, we infer that this rhythm is derived from a self-sustaining biological oscillator with a period of about a year, i.e., a circannual clock, analogous to the circadian clock. Furthermore, a circadian clock appears to mediate photoperiodic time measurement for phase resetting of the circannual clock. Based on these results and previous research performed in other organisms, we discuss the general characteristics of the physiological mechanisms underpinning circannual rhythmicity.
\end{abstract}

Keywords: Anthrenus verbasci; circannual clock; circannual rhythm; circadian clock; entrainment; phase response curve; photoperiodism; temperature compensation; zeitgeber. 


\section{Introduction}

Most organisms have evolved endogenous rhythms corresponding to various environmental cycles, including daily cycles, tidal cycles, and annual cycles, to enhance the rate of survival and reproduction. When isolated from external temporal cues, these biological rhythms free-run with an inherent period close to, but significantly different from, that of the environmental cycle. Appropriate environmental cues, i.e., zeitgebers, can entrain these endogenous rhythms to the environmental cycle (Pittendrigh, 1981a; Saunders, 2002; DeCoursey, 2004). The circadian rhythm, which has an endogenous period close to $24 \mathrm{~h}$ and entrains to daily cycles of light and temperature, has been studied by many researchers in a variety of organisms. Chronobiologists have started to uncover the mechanisms behind the biological clocks that generate rhythmicity, and today, the basic principles of circadian clocks are understood in detail (Saunders, 2002; Johnson et al., 2004; Stillman et al., 2007; Rosbash, 2009). However, compared to circadian rhythms, the sources of other endogenous rhythms are only partly understood, owing to a considerable lack of research. In particular, it is unclear whether the mechanism that generates internal periodicity is a self-sustaining biological oscillator similar to the circadian clock.

A biological rhythm with an endogenous period close to a year is called a circannual rhythm. The circannual rhythms of various physiological processes and behavioral traits have been reported in a variety of organisms, including dinoflagellates, brown algae, higher plants, coelenterates, annelids, mollusks, crustaceans, insects, fish, reptiles, birds, and mammals (Olive and Garwood, 1983; Gwinner, 1986; Goldman et al., 2004). In vertebrates, Pengelley and Fisher $(1957,1963)$ were the first to conclusively demonstrate the circannual rhythm of the golden-mantled ground squirrel, Spermophilus lateralis. The seasonal changes in body weight and food consumption, and the occurrence of hibernation, were shown to have a period shorter than 12 months when squirrels were maintained for 2 years under constant photoperiod (12-h light and 12-h darkness, LD 12:12) and temperature.

In invertebrates, Blake $(1958,1959)$ first reported that a circannual rhythm regulates pupation of the varied carpet beetle, Anthrenus verbasci (Insecta, Coleoptera, Dermestidae), which normally has a two-year life cycle in southern England. Moreover, she was the first to show the following major properties of the circannual rhythm (Blake, 1958, 1959, 1960, 1963): (1) a self-sustaining oscillation with a period deviating significantly from that of the environmental cycle; (2) temperature compensation of the period length; and (3) the existence of a zeitgeber entraining the rhythm to the environmental cycle and advance and delay 
phase-shifts induced by the stimulus (see also Gwinner, 1986; Saunders, 2002). The importance of Blake's work is comparable to the many studies of circannual rhythms carried out later in other animals, but has not received the attention it deserves (Saunders, 2002).

Since 1996, we have been examining the pupation rhythm in a Japanese population of A. verbasci. In Japan, the duration of the life cycle in this species is generally considered to be one year. In some cases, however, two or more years are required to complete larval development (Kiritani, 1958; Miyazaki et al., 2009a). We re-evaluated Blake’s results and introduced various new approaches based on our current knowledge of circadian and circannual rhythms and of photoperiodism. We found that the circannual rhythm of $A$. verbasci is generated by a circannual clock analogous to the circadian clock in its phase response (Nisimura and Numata, 2001; Miyazaki et al., 2005, 2007), and that the circannual rhythm, with a period of about 40 weeks, is entrained to an exact year by naturally changing photoperiods (Nisimura and Numata, 2003; Miyazaki et al., 2006). Moreover, the circannual clock is independent of the circadian clock (Nisimura and Numata, 2002), although a circadian clock is involved in the time measurement system for phase resetting of the circannual clock in response to photoperiodic changes (Miyazaki et al., 2009b).

Menaker (1974) stated that the major difficulty in the study of circannual rhythms is the ratio of the period length of a single circannual cycle to the length of the productive life of the biologist. Despite this difficulty, a number of researchers have studied circannual rhythms in a variety of species (Gwinner, 1986, 2003; Goldman et al., 2004; Paul et al., 2008; Wikelski et al., 2008; Lincoln and Hazlerigg, 2010). In this review, based on our results obtained in $A$. verbasci and those from studies on various other organisms, we discuss the general characteristics of the physiological mechanism producing circannual rhythmicity and its responsiveness to photoperiodic changes.

\section{Characteristics of the circannual rhythm}

\section{Self-sustainability}

Biological rhythms exhibit self-sustainability when examined under constant conditions without input from environmental cues (Pittendrigh, 1981a; Saunders, 2002; Johnson et al., 2004). A constant 24-h light-dark cycle has been used routinely to detect circannual rhythms, because unchanging photoperiods contain no information about the duration of a year (Gwinner, 1986). Figure 1A shows the frequency of pupation times of $A$. verbasci when 
larvae were reared under $\operatorname{LD} 12: 12$ at $20^{\circ} \mathrm{C}$. These insects exhibited rhythmic pupation. Larvae pupated 23-31 weeks after hatching as the first pupation group. The second group pupated 49-74 weeks after hatching. A third pupation group was observed 89-109 weeks after hatching. The interval between the medians of the first and second groups was 37 weeks, and that of the second and third groups was 37.5 weeks. This periodicity can be explained by the gate concept, which was originally introduced for the allowed time for eclosion in the circadian rhythm of flies (Pittendrigh, 1966). Thus, the existence of an endogenous circannual rhythm in the process of pupation was demonstrated in a Japanese population of $A$. verbasci (Nisimura and Numata, 2001). We repeated the experiments under LD 12:12 at $20^{\circ} \mathrm{C}$ from various times of the year and observed a similar rhythmicity, although the third pupation group has not been clearly observed in many cases (Nisimura and Numata, 2001, 2003; Miyazaki et al., 2005, 2009b). The timing of pupation in the first and second cycles was negligibly affected by slowing larval development with a diet of low-nutrient food, although the percentage of pupae in each cycle changed remarkably (Miyazaki et al., 2009a).

It has been reported that, for some species, circannual rhythms persist under constant light or darkness. For example, the circannual hibernation rhythm of S. lateralis persists with a period shorter than 12 months, irrespective of whether the lighting conditions are constant darkness, constant light, or LD 12:12 (Pengelley et al., 1976; see also Gwinner, 1986). Figure $1 \mathrm{~B}$ shows the frequency of pupation times of $A$. verbasci when larvae were continuously maintained under constant dim light. The periodic pattern was less clear than that under LD 12:12 (Nisimura and Numata, 2001). When we first obtained these results, we thought that this indistinct rhythm resulted from the damping of the circannual rhythm, as observed for the circadian eclosion rhythm under constant light in flies (Pittendrigh, 1966; Saunders, 2002). However, later experiments revealed that the circannual rhythm of $A$. verbasci clearly persists under constant light after pre-exposure to LD 12:12 for 8 weeks. The pattern of pupation was similar to that under continuous LD 12:12 (Fig. 2; Miyazaki and Numata, 2010). The circannual rhythmicity observed under constant light indicates that daily light-dark cycles are not necessary to sustain this endogenous rhythm, as observed in a British population under constant darkness (Blake, 1958, 1959). As described later, the change in the photoperiod is a zeitgeber for this circannual rhythm. It is likely that the circannual rhythm of A. verbasci oscillates under constant light, but the initial circannual phase of newly hatched larvae varies among individuals. Therefore, for a circannual rhythm to be clearly observed under constant light, it is necessary to synchronize the phase of the larvae by subjecting them to 24-h photoperiodic cycles. 
The circannual period of $A$. verbasci is $8-10$ months (Blake, 1959; Nisimura and Numata, 2001; Miyazaki et al., 2009b). The circannual periods under constant conditions are shorter than one year in many species, although longer periods have also been reported (Gwinner, 1986). Individual circannual periods often show great variability, even within a single species (Gwinner, 1986). The circannual period under constant dim light in the dark-eyed junco, Junco hyemalis, ranges from 6 to 20 months (mean, 13.7 months) in testicular development, and from 6 to 21 months (mean, 15.0 months) in the onset of post-nuptial molts (Holberton and Able, 1992). These deviations from 12 months, of about $-50 \%$ and $+75 \%$ in extreme cases, represent considerable variations, compared to deviations from $24 \mathrm{~h}$ of approximately $-13 \%$ (21 h) and $+17 \%$ (28 h) in circadian free-running periods (Aschoff, 1979). In addition, some species display circannual rhythms only under certain photoperiodic conditions (Gwinner, 1986, 1996; Schaffelke and Lüning, 1994; Paul et al., 2008). For example, the European starling, Sturnus vulgaris, shows a clear circannual rhythm in testicular development under LD 12:12, but not under LD 11:13 or LD 13:11 (Schwab, 1971). The circannual rhythm of $A$. verbasci was also obscure under LD 15:9 and LD 16:8, and arrhythmic under LD 14:10 (Nisimura and Numata, 2003). The influence of photoperiod on the circannual period has also been reported (Gwinner, 1986 for review). In the rainbow trout, Oncorhynchus mykiss, the circannual period is significantly shorter under LD 18:6 and constant light than under LD 6:18 (Duston and Bromage, 1986). The circannual period of $A$. verbasci was 5 weeks longer under LD 13:11 than under LD 12:12 (Nisimura and Numata, 2003). Under LD 10:14 in one experiment, the rhythm persisted with a much longer period of 52 weeks (Nisimura and Numata, 2002), but in another experiment, pupation after the first peak was asynchronous and the period length could not be determined (Miyazaki and Numata, 2009). Although circannual rhythms in some species, including the African stonechat, Saxicola torquatus, and the Siberian chipmunk, Tamias sibiricus, have been reported to persist for approximately ten years (Gwinner, 1996; Kondo et al., 2006), circannual rhythms in most organisms tend to dampen within several cycles under constant conditions in the laboratory (Gwinner, 1986). In general, both inter- and intra-individual variability in the endogenous period in the same species is considerably larger for most circannual rhythms than for circadian rhythms. Thus, Gwinner (1986) concluded that circannual rhythms have weaker self-sustainability than circadian rhythms.

\section{Temperature compensation}


Biological oscillators are based on intricate biochemical mechanisms. Although most biochemical processes depend on temperature, temperature compensation is required for accurate time measurement in biological rhythms (Pittendrigh, 1981a; Saunders, 2002; Johnson et al., 2004). Aperiodic fluctuations in temperature perturb time measurement and need to be eliminated by buffering mechanisms, i.e., compensation mechanisms. In fact, period length is almost fully temperature compensated in circadian rhythms under steady-state conditions at various constant temperatures (Sweeney and Hastings, 1960; Balzer and Hardeland, 1988; Saunders, 2002). In biological rhythms with longer periods, however, the demonstration of temperature compensation is sometimes difficult. Firstly, it is difficult to maintain strict constant conditions for a long duration, and secondly, a desired constant temperature under experimental conditions often interferes with the regulation of seasonal physiological events (Gwinner, 1986; Balzer and Hardeland, 1988). Nevertheless, temperature compensation has been reported in some circannual rhythms (Gwinner, 1986).

Temperature compensation was shown in the circannual rhythm period of a hibernating homeotherm, S. lateralis, which spends many months each year in deep torpor with a body temperature close to that of its environment. In this animal, although the period of the first circannual cycle during hibernation is slightly longer at $3^{\circ} \mathrm{C}$ than at $12^{\circ} \mathrm{C}$, this difference disappears in the second and third cycles (Pengelley and Asmundson, 1969). Much larger differences would have been expected if the processes underlying circannual rhythms showed a temperature dependence similar to that of many other physiological processes. These results suggest that the circannual period is, at least to a certain extent, temperature compensated (Gwinner, 1986).

More conspicuous examples of temperature-compensated circannual rhythms are present in poikilotherms (Gwinner, 1986). In our studies of A. verbasci, when larvae were exposed under LD 12:12, pupation began 21-27 weeks after hatching at constant temperatures between $17.5^{\circ} \mathrm{C}$ and $27.5^{\circ} \mathrm{C}$, and the second group pupated about 40 weeks after the first. High temperatures did not result in earlier pupation as might be expected from observations of normal developmental processes. In fact, the first pupation peaks were slightly delayed by higher temperature (Fig. 3; Nisimura and Numata, 2001). We concluded that the timing of pupation displayed temperature compensation, in line with the results of Blake (1958, 1959).

Temperature compensation of the circannual period has also been shown in various other invertebrates, e.g., oviposition of the slug, Limax flavus $\left(10-20^{\circ} \mathrm{C}\right.$; Segal, 1960; see also Gwinner, 1986), growth and development of the hydroid, Campanularia flexuosa $\left(10-24^{\circ} \mathrm{C}\right.$; 
Brock, 1975a, b), and sexual maturation of the polychaete, Nereis diversicolor $\left(5-10^{\circ} \mathrm{C}\right.$; Olive and Garwood, 1983). Thus, in invertebrates, compensation mechanisms appear to modulate time measurement in circannual rhythms under conditions of changing environmental temperature.

\section{Entrainability}

Biological rhythms can be entrained by zeitgebers from environmental cycles, thereby maintaining a stable phase relationship to environmental cycles (Pittendrigh, 1981a; Saunders, 2002; Johnson et al., 2004). In many species, a change in photoperiod is the dominant zeitgeber for entraining the circannual rhythm to an annual cycle (Gwinner, 1986; Goldman et al., 2004; Paul et al., 2008). For example, the circannual rhythms were entrained to sinusoidal photoperiodic cycles when the zeitgeber periods were 4-24 months and 2-12 months in antler replacement of the sika deer, Cervus nippon, and in testicular development of S. vulgaris, respectively (Goss, 1969; Gwinner, 1977; see also Gwinner, 1986). The circannual rhythms of growth in two kelp species, Pterygophora californica and Laminaria hyperborea, were also entrained to sinusoidal photoperiodic cycles with a period of 3-12 months (Lüning and Kadel, 1993; Schaffelke and Lüning, 1994). Although the endogenous period of circannual rhythms in many species often deviates considerably from 12 months, entrainment to the natural year is uneventfully accomplished by a range of entrainment proportionally much larger than that for circadian rhythms (Gwinner, 1986; Goldman et al., 2004). Gwinner (1986) suggested that at least some circannual rhythms with weaker self-sustainability were more dependent on environmental zeitgebers and more easily affected by them than circadian rhythms.

When we exposed $A$. verbasci larvae to natural annual changes in photoperiod in Japan, at a constant $20^{\circ} \mathrm{C}$, pupation peaks were observed in January or February in both the first and second cycles (Fig. 4A; Nisimura and Numata, 2003; Miyazaki et al., 2006), similar to the observations by Blake (1960) of A. verbasci populations in England. Therefore, a circannual pupation rhythm in $A$. verbasci, displaying a periodicity of about 40 weeks under LD 12:12, is entrained to exactly one year by exposure to natural changes in photoperiod.

Blake (1963) suggested that the first and second cycles of the pupation rhythm in $A$. verbasci were controlled differently. She argued that, in the first cycle, pupation was advanced by increasing day length, but that in the second cycle, pupation was inhibited by decreasing day length. However, our results obtained by altering continuous short day (LD 
12:12) and long day (LD 16:8) cycles at various time points indicate that whether pupation is advanced or delayed depends on the phase at which the photoperiodic stimulus is applied, rather than the cycle of the circannual rhythm (Nisimura and Numata, 2001; Miyazaki et al., 2005, 2007). Phase-dependent shifts in rhythm are important factors in entrainment and have been observed in many different circadian rhythms. This topic will be explored in detail later.

Compared to the photoperiod, the role of non-photoperiodic cues has not been sufficiently examined, although seasonal changes in temperature, daytime light intensity, and social stimuli have been suggested as potential zeitgebers in various species (Gwinner, 1986, 2003; Goldman et al., 2004; Paul et al., 2008). In many cases, non-photoperiodic cues act by directly driving or suppressing expression of the trait without entrainment of the endogenous rhythm (Paul et al., 2008). When A. verbasci larvae are exposed to natural fluctuations in light and temperature, they pupate each year in April, rather than in January and February (Nisimura and Numata, 2003; Miyazaki et al., 2009a). It is likely that low temperatures between December and March suppress pupation until April, and that this suppression also contributes to the synchrony of pupation in the field. However, there remains the possibility that natural temperature changes act as an effective zeitgeber for the circannual rhythm of $A$. verbasci, as suggested by Blake (1960).

\section{Three different hypotheses for circannual rhythm generation}

\section{Circannual clock hypothesis}

A simple hypothesis to explain the generation of the circannual rhythm assumes the existence of a self-sustaining biological oscillator with a period of about a year, i.e., a circannual clock, analogous to the circadian clock (Pengelley and Asmundson, 1974; Mrosovsky, 1978; Gwinner, 1981a). However, the most troublesome feature of this hypothesis is the long-term nature of the oscillator. Many animals exhibiting circannual rhythms, including hibernating mammals and migratory birds, have short life spans of a few years (Gwinner, 1986), and therefore it is difficult to examine the circannual clock hypothesis in these organisms. Then, the other two hypotheses that do not involve a circannual clock, as mentioned below, may have arisen. However, for A. verbasci, our data suggest that the pupation rhythm is generated by a circannual clock similar to the circadian clock, because the phase response curves obtained in this circannual rhythm share many similar features with phase response curves obtained in circadian rhythms (Miyazaki et al., 2005, 2007; and see later sections for detail). 
Frequency de-multiplication hypothesis

Gwinner (1973) proposed the frequency de-multiplication hypothesis, which states that circannual rhythms are derived from circadian rhythms through a process of frequency de-multiplication. In other words, organisms generate circannual rhythms by transforming the circadian periodicity of about a day to one cycle of about a year. The possibility that circadian rhythms are involved in the production of circannual rhythms is appealing, because circadian rhythms are a ubiquitous feature of animal physiology. Moreover, Gwinner (1973) observed a positive correlation between circadian and circannual periods under constant dim light in $S$. vulgaris.

The frequency de-multiplication hypothesis requires that the period of the circannual rhythm is proportional to the period of the entrained circadian rhythms. Therefore, rigorous tests of this hypothesis can be performed by exposing individuals to light-dark cycles of different periods $(\mathrm{T})$. We reared $A$. verbasci larvae under different constant photoperiods, ranging from $\mathrm{T}=20$ to $26 \mathrm{~h}$ (Nisimura and Numata, 2002). Because the range of entrainment in circadian rhythms is usually between $18 \mathrm{~h}$ and $30 \mathrm{~h}$ (Aschoff and Pohl, 1978), the circadian rhythms of the larvae should entrain to the LD 10:10, LD 10:14, and LD 10:16 photoperiods. Based on the result under LD 10:14 $(\mathrm{T}=24)$, in which the first group of larvae pupated 25 weeks after hatching, the frequency de-multiplication hypothesis predicts that pupation should occur 21 and 27 weeks after hatching under LD 10:10 $(T=20)$ and LD 10:16 $(T=26)$, respectively (Fig. 5). However, the first group of larvae pupated 27 weeks after hatching under LD 10:10 and 25 weeks after hatching under LD 10:16. Thus, there is no positive correlation between the period of the light-dark cycle and the timing of pupation in $A$. verbasci (Nisimura and Numata, 2002). To date, similar experiments have been performed in three species of birds and one mammal, but results supporting the frequency de-multiplication hypothesis have not been obtained (Gwinner, 1981b; Carmichael and Zucker, 1986; Wikelski et al., 2008).

Furthermore, circannual rhythms are exhibited by most individuals even after disruption of circadian activity patterns by ablating the suprachiasmatic nucleus in mammals, or the pineal gland in birds, which are the locations of the circadian pacemaker (e.g., Zucker et al., 1983; Pant and Chandola-Saklani, 1992). These results also do not support the frequency de-multiplication hypothesis. 


\section{Sequence of linked stages hypothesis}

There is the hypothesis that circannual rhythms merely result from a sequence of linked physiological stages, with each stage normally taking a given amount of time to complete and then leading to the next, and so on (i.e., a chain of interval timers). The last stage is linked back to the first (Mrosovsky, 1978). Circannual rhythms in some hibernators, e.g., the edible dormouse, Glis glis, the little pocket mouse, Perognathus longimembris, and the thirteen-lined ground squirrel, Spermophilus tridecemlineatus, can be explained by this hypothesis, but those in others cannot (Mrosovsky, 1978).

Mrosovsky (1974) suggested that a circannual clock and a sequence of stages can be characterized as a pendulum-type oscillator and a relaxation oscillator, respectively. However, because the latter is one-dimensional, the sequence of linked stages hypothesis cannot explain some features of phase resetting of rhythms (see Lakin-Thomas, 1995 for details; see also Oda et al., 2000), e.g., Type 0 resetting and arrhythmicity induced by a zeitgeber pulse in the circannual rhythm of $A$. verbasci (Miyazaki et al., 2005, 2007), which we discuss further in the following section.

\section{Phase response curves and the biological oscillator}

In circadian rhythms, the response to a zeitgeber depends on the phase subjected to the zeitgeber. Phase response curves (PRCs) are constructed to represent these phase-dependent responses. A circadian PRC is a plot of the magnitude of phase shifts (phase advances and delays) obtained by giving a light pulse at various phases of a free-running rhythm under constant darkness (Pittendrigh, 1981b; Johnson, 1999; Johnson et al., 2004). A light pulse in early subjective night generally delays a phase whereas a light pulse in late subjective night advances a phase. A pulse applied in subjective day has little or no effect on the phase. The strength of a light pulse, i.e., intensity, duration, or both, often changes the amplitude of phase shifts in the PRC. Strong pulses produce Type 0 PRCs with large phase shifts and a distinct break point at the transition between delays and advances, whereas weak pulses produce Type 1 PRCs with small phase shifts and a continuous transition between phase delays and advances (Fig. 6A, B).

In contrast to circadian rhythms, reports of PRCs to zeitgeber pulses in circannual rhythms are uncommon (Paul et al., 2008). In the circannual spawning rhythm of the rainbow trout, Oncorhynchus mykiss, a pulse of constant light for 2 months induced a 
phase-dependent phase shift. However, because the treatment was performed on the rhythm entrained to naturally changing day length, the response curve obtained did not satisfy the definition of the PRC, in which a free-running rhythm is perturbed under constant conditions (Randall et al., 1998).

To construct a complete PRC to photoperiod pulses for a circannual rhythm, we kept $A$. verbasci larvae under LD 12:12 and exposed the larvae to LD 16:8 for 4 weeks (4-week long-day pulse) during various phases of the rhythm (Miyazaki et al., 2005). When larvae were exposed to a 4-week long-day pulse, 4 weeks after hatching, pupation of the first and second groups was delayed by 9-9.5 weeks, compared to control insects (Fig. 7B). However, when a 4-week long-day pulse was given 16 weeks after hatching, pupation was advanced by 2-3 weeks in both groups (Fig. 7C). Thus, whether a 4-week long-day pulse advances or delays the phase of the circannual rhythm depends on the phase in which the pulse is given. Based on these observations, we constructed a circannual PRC (Fig. 6C) where the period of the rhythm under continuous LD 12:12 (37 weeks; Fig. 7A) is shown in terms of angle degrees $\left(0-360^{\circ}\right)$. The initial phase under LD 12:12, i.e., the beginning of this experiment, is represented as $180^{\circ}$. The range $0-180^{\circ}$ is considered subjective summer and $180-360^{\circ}$ is considered subjective winter. This circannual PRC to 4-week long-day pulses closely resembles the Type 0 PRC of circadian rhythms (Fig. 6A, C).

We also constructed a circannual PRC to 2-week long-day pulses (Fig. 6D). The phase shifts are relatively smaller than those caused by a 4-week long-day pulse, and a PRC to 2-week long-day pulses has a continuous transition between delays and advances in the middle of the subjective winter. Therefore, this curve is categorized as Type 1 (Miyazaki et al., 2007).

In circadian rhythms, the two types of phase resetting, dependent on the strength of the zeitgeber stimulus, can be theoretically explained by the concept that a circadian clock is a biological oscillator that has two or more state variables. A number of different oscillator types have been proposed, including an adjustable-amplitude oscillator, a limit cycle oscillator, and a multi-oscillator system (Lakin-Thomas, 1995; Winfree, 2000; Johnson et al., 2004). It is known that arrhythmicity of a circadian rhythm can be evoked by a single light pulse of a certain strength delivered near the middle of the subjective night. This phenomenon can be explained by the notion that the oscillator is driven to the phaseless singularity in the phase space or that the phases of individual oscillators of the multi-oscillator system are scattered (Winfree, 1970, 2000; Lakin-Thomas, 1995; Johnson et al., 2004). In the circannual rhythm of A. verbasci, arrhythmicity of pupation can also be 
evoked by a 4-week long-day pulse administered in the middle of the subjective winter (Miyazaki et al., 2007). According to the theoretical explanations for Type 1 and Type 0 phase resetting and the loss of rhythmicity induced by a zeitgeber pulse, the mechanism behind the circannual rhythm of $A$. verbasci is thought to be a biological oscillator with two or more state variables with circannual variation (Lakin-Thomas, 1995; Johnson et al., 2004). This implies that the circannual rhythm of $A$. verbasci is generated by a circannual clock specialized for adaptation to annual cycles, much like the circadian clock and its adaptation to daily cycles.

Recently, a circannual PRC for reproduction in the European hamster, Cricetus cricetus, was constructed by exposing hamsters, normally maintained under long days (LD 16:8), to short days (LD 10:14) for 1 month (Monecke et al., 2009). The shape of the PRC was nearly identical to the circannual PRC to LD 16:8 for 4 weeks in A. verbasci, a species taxonomically quite distant from $C$. cricetus. Therefore, these phase responses may signify a fundamental and common characteristic of circannual rhythms, and the concept that the circannual rhythm is produced by a circannual clock specialized for annual cycles seems to be applicable to many diverse organisms.

\section{Photoperiodism for entrainment}

\section{Entrainment under natural day length}

The circannual rhythm of $A$. verbasci shows endogenous periodicity of about 40 weeks under continuous LD 12:12, but is entrained to a strictly annual period by changes in photoperiod. This entrainment can be explained as a phase delay induced by a decrease in day length in late summer or early autumn (Nisimura and Numata, 2001, 2003). However, it is necessary to know the exact temporal changes in the phase of the circannual clock under natural day length to understand the biological entrainment mechanisms operating under natural conditions.

If we compare the phase shifts induced by the photoperiod pulse under natural photoperiod with those shown in the circannual PRC, we can describe the temporal change in phase under natural day length in terms of the phase in the PRC. Therefore, we examined the phase responses to 4-week long-day pulses given between 4 August and 24 November under natural day length at a constant temperature of $20^{\circ} \mathrm{C}$ (Miyazaki et al., 2006). These pulses caused a phase shift in the first pupation group, as under LD 12:12. A long-day pulse given 
on 4 August, 1 September, or 29 September caused a phase delay, and a pulse given on 27 October or 24 November caused a phase advance. Pupation was least synchronous just before the transition from delay to advance (Fig. 4). These phase responses were similar to those in the subjective winter of a circannual PRC to 4-week long-day pulses under LD 12:12 (Fig. 6C). Therefore, the circannual clock changes its phase at least from early August to late November under natural day length, as occurs in the subjective winter under LD 12:12. In the second pupation group, however, larvae pupated at the same time as control larvae not subjected to a long-day pulse, regardless of the phase response of the first group (Fig. 4). This result can be explained by entrainment to the geophysical year by long days during spring and summer.

We also examined the range of photoperiodic changes effective for circannual phase shifts in A. verbasci by exposing larvae to various longer photophases for 4 weeks against a background of LD 12:12 or LD 10:14 (Miyazaki and Numata, 2009). Phase advances were smaller than phase delays and the magnitude of the change depended on the amplitude of the photoperiodic changes rather than the absolute photophase duration. In contrast, a clear phase delay was induced when the photoperiodic change exceeded a critical value in the photophase between 13 and $14 \mathrm{~h}$, regardless of the amplitude of the change. It is likely that the response in phase delay is more important in the seasonal timing of pupation under natural conditions because the endogenous period of this rhythm is considerably shorter than one year. In photoperiodic responses of many species, an important feature is the existence of a critical day length above or below which behavioral and physiological responses are observed (Saunders, 2002; Goldman et al., 2004; Nelson et al., 2010). To entrain a circannual period to the natural annual cycle, A. verbasci in central Japan probably uses a critical value in the photophase between 13 and $14 \mathrm{~h}$ for determining whether the day length is long or short. It is thought that stable entrainment to the natural year is established by giving long-term exposure to a photophase longer than $13 \mathrm{~h}$ during spring and summer, or during late subjective summer or early subjective winter of the circannual rhythm, where phase delay responses to long days are exhibited in the PRC (Figs. 4A and 6C).

An important role of long days in summer has also been suggested in entrainment of the circannual rhythm in luteinizing hormone secretion of the sheep, Ovis aries (Woodfill et al., 1994). In pinealectomized ewes, which do not respond to changes of day length, photoperiodic information was applied during one of the four seasons each year via infusion of melatonin, a hormone that mediates the effects of the photoperiod. The infusion was designed to simulate season-specific melatonin secretion. Infusion during the summer was 
most effective in entrainment to annual cycles and maintained the proper relationship between the phase of the rhythm and the season during which the infusion was provided.

The response and phase setting of circannual rhythms to photoperiodic changes likely varies, depending on the species or subspecies (Gwinner, 1986; Helm et al., 2009). To better understand the full diversity of responses of circannual rhythms to photoperiodic changes, further research will be required in a wide variety of species.

\section{Involvement of a circadian clock}

A wide variety of species have evolved photoperiodism without relation to circannual rhythms. In such photoperiodism, the photoperiodic time measurement system generally involves a circadian clock (Saunders, 2002; Goldman et al., 2004; Nelson et al., 2010). In phase responses in the circannual rhythm of $A$. verbasci, photoperiodic time measurement is also necessary, although unlike regular photoperiodism, the effects of photoperiod are indirect and are due to resetting of the circannual rhythm. The Nanda-Hamner protocol has frequently been used to clarify the involvement of a circadian system in photoperiodic responses. In this protocol, groups of organisms are subjected to light-dark cycles with a fixed short photophase followed by a variable scotophase to give cycle lengths (T) of up to $72 \mathrm{~h}$ or more. If organisms show short-day responses when $\mathrm{T}$ is a multiple of $24 \mathrm{~h}$, but not when $\mathrm{T}$ is not a multiple of $24 \mathrm{~h}$, the response is considered positive, thus indicating the involvement of a circadian system in photoperiodic time measurement.

The Nanda-Hamner protocol has been used to examine the reproductive activities of several vertebrate species exhibiting circannual rhythms. In O. mykiss, the effects of constant 48-h, 54-h, and 60-h photoperiods were examined over 2 years, but the circadian nature of the photoperiodic responses was obscure (Duston and Bromage, 1986). Positive responses to the Nanda-Hamner protocol were demonstrated for birds and mammals (e.g., Gwinner and Eriksson, 1977; Almeida and Lincoln, 1982), although these observations were conducted over a period of less than a year.

We examined the effects of exposure to the Nanda-Hamner protocol (LD 12:12, LD 12:24, LD 12:36, LD 12:48, and LD 12:60) on the circannual rhythm of A. verbasci to examine whether the circadian system is involved in photoperiodic time measurement for entrainment (Miyazaki et al., 2009b). Figure 8 shows the results when larvae were exposed to various photoperiods for 120 days and then transferred to LD 12:12. When larvae were exposed to LD 12:36 or LD 12:60, for which $\mathrm{T}$ is a multiple of $24 \mathrm{~h}$, the pupation pattern was 
similar to that under continuous LD 12:12. In contrast, under LD 12:24 ( $\mathrm{T}=36 \mathrm{~h}$ ), the pupation pattern was similar to that under LD 16:8, being considerably delayed compared to that under LD 12:12. Under LD 12:48 $(\mathrm{T}=60 \mathrm{~h})$, pupation was also delayed and was less synchronous than that of the first group under LD 12:60 ( $\mathrm{T}=72 \mathrm{~h})$ or constant darkness. Thus, photoperiods for which T was not a multiple of 24 h (i.e., LD 12:24 and LD 12:48) produced a large phase delay compared to LD 12:12. These results clearly indicate that the circannual rhythm of $A$. verbasci shows a positive Nanda-Hamner response in phase resetting to photoperiod. Therefore, a circadian clock is most likely involved in photoperiodic entrainment of this rhythm, although it is not responsible for generating the circannual rhythm, as described above.

\section{Conclusions and future directions}

In the circannual pupation rhythm of $A$. verbasci, we confirmed self-sustainability (i.e., persistence), temperature compensation of the period, and entrainability to a zeitgeber (Nisimura and Numata, 2001), all of which are key characteristics of a clock mechanism linked to environmental cycles (Pittendrigh, 1981a; Saunders, 2002; Johnson et al., 2004). The characteristics of this rhythm indicate that the frequency de-multiplication hypothesis does not accurately describe the underlying mechanism (Nisimura and Numata, 2002). The circannual PRCs were obtained by giving long-day pulses, and the shapes of the curves closely resembled those of circadian PRCs to light pulses (Miyazaki et al., 2005, 2007). Similarities to circadian rhythms in the resetting patterns indicate that the mechanism producing circannual rhythmicity in $A$. verbasci is a circannual clock analogous to the circadian clock (Miyazaki et al., 2007).

The circannual clock has most likely evolved to increase the chances of survival and reproductive success, by allowing the organism to better predict and adapt to seasonal changes (Pittendrigh, 1981a; Gwinner, 1981a, 1986; DeCoursey, 2004). To permit accurate and consistent seasonal responses, $A$. verbasci refers not only to ambient photoperiod, but also to the phase of a circannual clock (Miyazaki et al., 2006), and it refers to a circadian clock to judge photoperiod (Miyazaki et al., 2009b). Figure 9 shows a schematic diagram of the physiological system behind the circannual rhythm of $A$. verbasci. Thus, in the field, an annual rhythm of $A$. verbasci is established by a combination of exogenous factors and endogenous physiological mechanisms comprising circadian and circannual clocks. It is likely that this schema is also applicable to certain other organisms, e.g., O. aries (Lincoln et 
al., 2006; Lincoln and Hazlerigg, 2010).

The neural and molecular mechanisms that generate circannual rhythmicity remain unknown, not only for A. verbasci, but for other species as well. In S. lateralis, various neural tissues and endocrine glands, including the suprachiasmatic nucleus and the pineal gland, have been ablated, but the anatomical location of the circannual pacemaker is still unclear (Zucker, 2001). In O. aries, however, Lincoln et al. (2006) suggested that the adenohypophysis is the site of the pacemaker for the circannual rhythm of prolactin secretion. The adenohypophysis secrets prolactin with circannual periodicity, without neural inputs from the brain, and is a target of pineal melatonin signals transmitting photoperiodic information.

Recently, a few models have been proposed to generate the circannual rhythm in mammals. In T. sibiricus, the complex of hibernation-specific proteins is secreted by the liver. Before hibernation, this complex is transported to the brain where it mediates the onset of hibernation (Kondo et al., 2006). For circannual rhythm generation in this species, Kondo (2007) proposed a model in which levels of this hibernation-specific protein complex in the brain and periphery form a negative feedback loop. In the circannual rhythm of $O$. aries, MacGregor and Lincoln (2008) proposed a physiological model consisting of a negative feedback mechanism comprising the components of the pars tuberalis and pars distalis within the adenohypophysis. These two models postulates a negative feedback loop formed by a number of different tissues. In contrast, Lincoln and Hazlerigg (2010) proposed that circannual rhythmicity is autonomously generated by cyclical histogenesis in specific sites in various tissues, such as the brain, pituitary, and periphery.

Because circannual rhythms have also been observed in coelenterates (Brock, 1975a), it is possible that animals can exhibit circannual rhythmicity without the need for a central nervous system. Furthermore, circannual rhythms are observed even in eukaryotic unicellular organisms, and therefore, molecular feedback loops within a single cell, similar to those in a circadian clock, may be involved in generating the circannual rhythm (Anderson and Keafer, 1987; Matrai et al., 2005). If circannual rhythms have evolved independently several times and are of heterogeneous origin in different groups of organisms (Farner, 1970; Gwinner, 1981a, 1986), entirely different mechanisms may drive the circannual rhythm in different species.

Several approaches are available to uncover the mechanism behind circannual rhythmicity in A. verbasci. Because a photoperiodic response involving a circadian system resets the phase of a circannual clock in this species (Fig. 9), one way is to identify the 
anatomical location of a circannual clock by reference to the centers for photoperiodism and circadian rhythmicity. One may proceed by studying the expression and regulation of circadian clock genes, similar to the approach used to unravel the molecular mechanisms of insect photoperiodism (Goto et al., 2010). Another method is provided by studies in birds. In avian circannual rhythms, there are clear differences in the degree of rhythmicity, timing of behavior, and responsiveness to photoperiod among populations living in different areas. This geographic variation is clearly attributable to genetic differences, because crossbreeding produces an intermediate response in the hybrid progeny (Gwinner, 1986, 1996; Helm et al., 2009). A. verbasci is a geographically widespread species, and therefore, it probably also has genetic variation. The genetic differences may help in elucidating the molecular mechanisms of circannual rhythmicity in this organism.

A direct way to identify molecular candidates involved in the generation of circannual rhythmicity is to use DNA microarrays, similar to approaches used to identify candidates that play a role in circadian rhythm generation (McDonald and Rosbash, 2001; Akhtar et al., 2002). Subsequently, the precise involvement of the candidates in the circannual rhythm may be revealed by RNA interference (RNAi). In beetles, inhibition of gene expression in various physiological responses has been performed by RNAi (e.g., Tomoyasu and Denell, 2004; Niimi et al., 2005). Therefore, we propose DNA microarrays and RNAi as the next step to clarify the biological mechanism behind the circannual rhythm in A. verbasci.

Since Konopka and Benzer (1971) first demonstrated that a gene, called period, regulates the circadian behavior of the fruit fly, Drosophila melanogaster, enormous advances in our knowledge of the genetic and molecular aspects of circadian rhythmicity have occurred. A clear picture of the underlying molecular feedback loops is emerging for numerous organisms (Saunders, 2002; Rosbash, 2009). We anticipate that our knowledge of the physiological and molecular mechanisms behind circannual rhythmicity will similarly advance greatly when researchers begin to isolate the molecular components of this fundamental biological process. 


\section{References}

Akhtar, R. A., Reddy, A. B., Maywood, E. S., Clayton, J. D., King, V. M., Smith, A. G., et al. (2002). Circadian cycling of the mouse liver transcriptome, as revealed by cDNA microarray, is driven by the suprachiasmatic nucleus. Current Biology, 12, 540-550.

Almeida, O. F., \& Lincoln, G. A. (1982). Photoperiodic regulation of reproductive activity in the ram: Evidence for the involvement of circadian rhythms in melatonin and prolactin secretion. Biology of Reproduction, 27, 1062-1075.

Anderson, D. M., \& Keafer, B. A. (1987). An endogenous annual clock in the toxic marine dinoflagellate Gonyaulax tamarensis. Nature, 325, 616-617.

Aschoff, J. (1979). Circadian rhythms: Influences of internal and external factors on the period measured in constant conditions. Zeitschrift für Tierpsychologie, 49, 225-249.

Aschoff, J., \& Pohl, H. (1978). Phase relations between a circadian rhythm and its zeitgeber within the range of entrainment. Naturwissenschaften, 65, 80-84.

Balzer, I., \& Hardeland, R. (1988). Influence of temperature on biological rhythms. International Journal of Biometeorology, 32, 231-241.

Blake, G. M. (1958). Diapause and the regulation of development in Anthrenus verbasci (L.) (Col., Dermestidae). Bulletin of Entomological Research, 49, 751-775.

Blake, G. M. (1959). Control of diapause by an 'internal clock' in Anthrenus verbasci (L.) (Col., Dermestidae). Nature, 183, 126-127.

Blake, G. M. (1960). Decreasing photoperiod inhibiting metamorphosis in an insect. Nature, 188, 168-169.

Blake, G. M. (1963). Shortening of a diapause-controlled life cycle by means of increasing photoperiod. Nature, 198, 462-463.

Brock, M. A. (1975a). Circannual rhythms-I. Free-running rhythms in growth and development of the marine cnidarian, Campanularia flexuosa. Comparative Biochemistry and Physiology, 51A, 377-383.

Brock, M. A. (1975b). Circannual rhythms-II. Temperature-compensated free-running rhythms in growth and development of the marine cnidarian, Campanularia flexuosa. Comparative Biochemistry and Physiology, 51A, 385-390.

Carmichael, M. S., \& Zucker, I. (1986). Circannual rhythms of ground squirrels: A test of the frequency demultiplication hypothesis. Journal of Biological Rhythms, 1, 277-284.

DeCoursey, P. J. (2004). The behavioral ecology and evolution of biological timing systems. 
In J. C. Dunlap, J. J. Loros \& P. J. DeCoursey (Eds.), Chronobiology - Biological timekeeping (pp. 27-65). Sunderland: Sinauer Associates.

Duston, J., \& Bromage, N. (1986). Photoperiodic mechanisms and rhythms of reproduction in the female rainbow trout. Fish Physiology and Biochemistry, 2, 35-51.

Farner, D. S. (1970). Predictive functions in the control of annual cycles. Environmental Research, 3, 119-131.

Goldman, B., Gwinner, E., Karsch, F. J., Saunders, D., Zucker, I., \& Gall, G. F. (2004). Circannual rhythms and photoperiodism. In J. C. Dunlap, J. J. Loros \& P. J. DeCoursey (Eds.), Chronobiology - Biological timekeeping (pp. 107-142). Sunderland: Sinauer Associates.

Goss, R. J. (1969). Photoperiodic control of antler cycles in deer. I. Phase shift and frequency changes. Journal of Experimental Zoology, 170, 311-324.

Goto, S. G., Shiga, S., \& Numata, H. (2010). Photoperiodism in insects: Perception of light and the role of clock genes. In R. J. Nelson, D. L. Denlinger \& D. E. Somers (Eds.), Photoperiodism: The biological calendar (pp. 258-286). New York: Oxford University Press.

Gwinner, E. (1973). Circannual rhythms in birds: Their interaction with circadian rhythms and environmental photoperiod. Journal of Reproduction and Fertility (Supplement), 19, $51-65$.

Gwinner, E. (1977). Photoperiodic synchronization of circannual rhythms in the European starling (Sturnus vulgaris). Naturwissenschaften, 64, 44-45.

Gwinner, E. (1981a). Circannual systems. In J. Aschoff (Ed.), Handbook of behavioral neurobiology, Vol. 4, Biological rhythms (pp. 391-410). New York: Plenum Press.

Gwinner, E. (1981b). Circannual rhythms: Their dependence on the circadian system. In B. K. Follett \& D. E. Follett (Eds.), Biological clocks in seasonal reproductive cycles (pp. 153-169). Bristol: John Wright \& Sons.

Gwinner, E. (1986). Circannual rhythms. Berlin: Springer-Verlag.

Gwinner, E. (1996). Circannual clocks in avian reproduction and migration. Ibis, 138, 47-63.

Gwinner, E. (2003). Circannual rhythms in birds. Current Opinion in Neurobiology, 13, $770-778$.

Gwinner, E., \& Eriksson, L. O. (1977). Circadiane Rhythmik und photoperiodische Zeitmessung beim Star (Sturnus vulgaris). Journal of Ornithology, 118, 60-67.

Helm, B., Schwabl, I., \& Gwinner, E. (2009). Circannual basis of geographically distinct bird schedules. The Journal of Experimental Biology, 212, 1259-1269. 
Holberton, R. L., \& Able, K. P. (1992). Persistence of circannual cycles in a migratory bird held in constant dim light. Journal of Comparative Physiology A, 171, 477-481.

Johnson, C. H. (1999). Forty years of PRCs - What have we learned? Chronobiology International, 16, 711-743.

Johnson, C. H., Elliott, J., Foster, R., Honma, K. I., \& Kronauer, R. (2004). Fundamental properties of circadian rhythms. In J. C. Dunlap, J. J. Loros \& P. J. DeCoursey (Eds.), Chronobiology - Biological timekeeping (pp. 67-105). Sunderland: Sinauer Associates.

Kiritani, K. (1958). Factors influencing the development of Anthrenus verbasci L. Botyu-Kagaku, 23, 137-146. (In Japanese, abstract in English.)

Kondo, N. (2007). Endogenous circannual clock and HP complex in a hibernation control system. In Clocks and rhythms: Cold Spring Harbor symposia on quantitative biology, Vol. 72 (pp. 607-613). Woodbury NY: Cold Spring Harbor Laboratory Press.

Kondo, N., Sekijima, T., Kondo, J., Takamatsu, N., Tohya, K., \& Ohtsu, T. (2006). Circannual control of hibernation by HP complex in the brain. Cell, 125, 161-172.

Konopka, R. J., \& Benzer, S. (1971). Clock mutants of Drosophila melanogaster. Proceedings of the National Academy of Sciences of the United States of America, 68, 2112-2116.

Lakin-Thomas, P. L. (1995). A beginner's guide to limit cycles, their uses and abuses. Biological Rhythm Research, 26, 216-232.

Lincoln, G. A., \& Hazlerigg, D. G. (2010). Mammalian circannual pacemakers. In M. C. Lucy, J. L. Pate, M. F. Smith \& T. E. Spencer (Eds.), Reproduction in domestic ruminants, Vol. 7 (pp. 171-186). Nottingham: Nottingham University Press.

Lincoln, G. A., Clarke, I. J., Hut, R. A., \& Hazlerigg, D. G. (2006). Characterizing a mammalian circannual pacemaker. Science, 314, 1941-1944.

Lüning, K., \& Kadel, P. (1993). Daylength range for circannual rhythmicity in Pterygophora californica (Alariaceae, Phaeophyta) and synchronization of seasonal growth by daylength cycles in several other brown algae. Phycologia, 32, 379-387.

MacGregor, D. J., \& Lincoln, G. A. (2008). A physiological model of a circannual oscillator. Journal of Biological Rhythms, 23, 252-264.

Matrai, P., Thompson, B., \& Keller, M. (2005). Circannual excystment of resting cysts of Alexandrium spp. from eastern Gulf of Maine populations. Deep-Sea Research Part II: Topical Studies in Oceanography, 52, 2560-2568.

McDonald, M. J., \& Rosbash, M. (2001). Microarray analysis and organization of circadian gene expression in Drosophila. Cell, 107, 567-578. 
Menaker, M. (1974). Circannual rhythms in circadian perspective. In E. T. Pengelley (Ed.), Circannual clocks: Annual biological rhythms (pp. 507-518). New York: Academic Press.

Miyazaki, Y., \& Numata, H. (2009). Responsiveness to photoperiodic changes in the circannual rhythm of the varied carpet beetle, Anthrenus verbasci. Journal of Comparative Physiology A, 195, 241-246.

Miyazaki, Y., \& Numata, H. (2010). Exhibition of circannual rhythm under constant light in the varied carpet beetle Anthrenus verbasci. Biological Rhythm Research, 41, 441-448. Miyazaki, Y., Nisimura, T., \& Numata, H. (2005). A phase response curve for circannual rhythm in the varied carpet beetle Anthrenus verbasci. Journal of Comparative Physiology A, 191, 883-887.

Miyazaki, Y., Nisimura, T., \& Numata, H. (2006). Phase responses in the circannual rhythm of the varied carpet beetle, Anthrenus verbasci, under naturally changing day length. Zoological Science, 23, 1031-1037.

Miyazaki, Y., Nisimura, T., \& Numata, H. (2007). Phase resetting and phase singularity of an insect circannual oscillator. Journal of Comparative Physiology A, 193, 1169-1176.

Miyazaki, Y., Nisimura, T., \& Numata, H. (2009a). Circannual pupation rhythm in the varied carpet beetle Anthrenus verbasci under different nutrient conditions. Entomological Science, 12, 370-375.

Miyazaki, Y., Nisimura, T., \& Numata, H. (2009b). A circadian system is involved in photoperiodic entrainment of the circannual rhythm of Anthrenus verbasci. Journal of Insect Physiology, 55, 494-498.

Monecke, S., Saboureau, M., Malan, A., Bonn, D., Masson-Pévet, M., \& Pévet, P. (2009). Circannual phase response curves to short and long photoperiod in the European hamster. Journal of Biological Rhythms, 24, 413-426.

Mrosovsky, N. (1974). Comment. In E. T. Pengelley (Ed.), Circannual clocks: Annual biological rhythms (pp. 161-163). New York: Academic Press.

Mrosovsky, N. (1978). Circannual cycles in hibernators. In L. C. H. Wang \& J. W. Hudson (Eds.), Strategies in cold: Natural torpidity and thermogenesis (pp. 21-65). New York: Academic Press.

Nelson, R. J., Denlinger, D. L., \& Somers, D. E. (Eds.) (2010). Photoperiodism: The biological calendar. New York: Oxford University Press.

Niimi, T., Kuwayama, H., \& Yaginuma, T. (2005). Larval RNAi applied to the analysis of postembryonic development in the ladybird beetle, Harmonia axyridis. Journal of 
Insect Biotechnology and Sericology, 74, 95-102.

Nisimura, T., \& Numata, H. (2001). Endogenous timing mechanism controlling the circannual pupation rhythm of the varied carpet beetle Anthrenus verbasci. Journal of Comparative Physiology A, 187, 433-440.

Nisimura, T., \& Numata, H. (2002). Evaluation of the frequency demultiplication hypothesis of circannual pupation rhythm in the varied carpet beetle Antherenus verbasci (Coleoptera: Dermestidae). Biological Rhythm Research, 33, 255-260.

Nisimura, T., \& Numata, H. (2003). Circannual control of the life cycle in the varied carpet beetle Anthrenus verbasci. Functional Ecology, 17, 489-495.

Oda, G. A., Caldas, I. L., Piqueira, J. R. C., Waterhouse, J. M., \& Marques, M. D. (2000). Coupled biological oscillators in a cave insect. Journal of Theoretical Biology, 206, $515-524$.

Olive, P. J. W., \& Garwood, P. R. (1983). The importance of long term endogenous rhythms in the maintenance of reproductive cycles of marine invertebrates: A reappraisal. International Journal of Invertebrate Reproduction, 6, 339-347.

Pant, K., \& Chandola-Saklani, A. (1992). Pinealectomy and LL abolished circadian perching rhythms but did not alter circannual reproductive or fattening rhythms in finches. Chronobiology International, 9, 413-420.

Paul, M. J., Zucker, I., \& Schwartz, W. J. (2008). Tracking the seasons: The internal calendars of vertebrates. Philosophical Transactions of the Royal Society B, 363, 341-361.

Pengelley, E. T., \& Asmundson, S. M. (1969). Free-running periods of endogenous circannian rhythms in the golden mantled ground squirrel, Citellus lateralis. Comparative Biochemistry and Physiology, 30, 177-183.

Pengelley, E. T., \& Asmundson, S. J. (1974). Circannual rhythmicity in hibernating mammals. In E. T. Pengelley (Ed.), Circannual clocks: Annual biological rhythms (pp. 95-160). New York: Academic Press.

Pengelley, E. T., \& Fisher, K. C. (1957). Onset and cessation of hibernation under constant temperature and light in the golden-mantled ground squirrel, Citellus lateralis. Nature, 180, 1371-1372.

Pengelley, E. T., \& Fisher, K. C. (1963). The effect of temperature and photoperiod on the yearly hibernating behavior of captive golden-mantled ground squirrels (Citellus lateralis tescorum). Canadian Journal of Zoology, 41, 1103-1120.

Pengelley, E. T., Asmundson, S. J., Barnes, B., \& Aloia, R. C. (1976). Relationship of light intensity and photoperiod to circannual rhythmicity in the hibernating ground squirrel, 
Citellus lateralis. Comparative Biochemistry and Physiology, 53A, 273-277.

Pittendrigh, C. S. (1966). The circadian oscillation in Drosophila pseudoobscura pupae: A model for the photoperiodic clock. Zeitschrift für Pflanzenphysiologie, 54, 275-307. Pittendrigh, C. S. (1981a). Circadian systems: General perspective. In J. Aschoff (Ed.), Handbook of behavioral neurobiology, Vol. 4, Biological rhythms (pp. 57-80). New York: Plenum Press.

Pittendrigh, C. S. (1981b). Circadian systems: Entrainment. In J. Aschoff (Ed.), Handbook of behavioral neurobiology, Vol. 4, Biological rhythms (pp. 95-124). New York: Plenum Press.

Randall, C. F., Bromage, N. R., Duston, J., \& Symes, J. (1998). Photoperiod-induced phase-shifts of the endogenous clock controlling reproduction in the rainbow trout: A circannual phase-response curve. Journal of Reproduction and Fertility, 112, 399-405.

Rosbash, M. (2009). The implications of multiple circadian clock origins. PLoS Biology, 7, e1000062.

Saunders, D. S. (2002). Insect clocks (3rd ed.). Amsterdam: Elsevier.

Schaffelke, B., \& Lüning, K. (1994). A circannual rhythm controls seasonal growth in the kelps Laminaria hyperborea and L. digitata from Helgoland (North Sea). European Journal of Phycology, 29, 49-56.

Schwab, R. G. (1971). Circannian testicular periodicity in the European starling in the absence of photoperiodic change. In M. Menaker (Ed.), Biochronometry (pp. 428-447). Washington DC: National Academy of Sciences.

Segal, E. (1960). Discussion to the paper of A J Marshall. In Biological clocks: Cold Spring Harbor symposia on quantitative biology, Vol. 25 (pp. 504-505). Cold Spring Harbor: The Biological Laboratory.

Stillman, B., Stewart, D., \& Grodzicker, T. (Eds.) (2007). Clocks and rhythms: Cold Spring Harbor symposia on quantitative biology, Vol. 72. Woodbury NY: Cold Spring Harbor Laboratory Press.

Sweeney, B. M., \& Hastings, J. W. (1960). Effects of temperature upon diurnal rhythms. In Biological clocks: Cold Spring Harbor symposia on quantitative biology, Vol. 25 (pp. 87-104). Cold Spring Harbor: The Biological Laboratory.

Tomoyasu, Y., \& Denell, R. E. (2004). Larval RNAi in Tribolium (Coleoptera) for analyzing adult development. Development Genes and Evolution, 214, 575-578.

Wikelski, M., Martin, L. B., Scheuerlein, A., Robinson, M. T., Robinson, N. D., Helm, B., et al. (2008). Avian circannual clocks: Adaptive significance and possible involvement of 
energy turnover in their proximate control. Philosophical Transactions of the Royal Society $B, 363,411-423$.

Winfree, A. T. (1970). Integrated view of resetting a circadian clock. Journal of Theoretical Biology, 28, 327-374.

Winfree, A. T. (2000). The geometry of biological time (2nd ed.). New York: Springer-Verlag.

Woodfill, C. J., Wayne, N. L., Moenter, S. M., \& Karsch, F. J. (1994). Photoperiodic synchronization of a circannual reproductive rhythm in sheep: Identification of season-specific time cues. Biology of Reproduction, 50, 965-976.

Zucker, I. (2001). Circannual rhythms: Mammals. In J. S. Takahashi, F. W. Turek \& R. Y. Moore (Eds.), Handbook of behavioral neurobiology, Vol. 12, Circadian clocks (pp. 509-528). New York: Kluwer Academic/Plenum.

Zucker, I., Boshes, M., \& Dark, J. (1983). Suprachiasmatic nuclei influence circannual and circadian rhythms of ground squirrels. American Journal of Physiology, 244, R472-R480. 


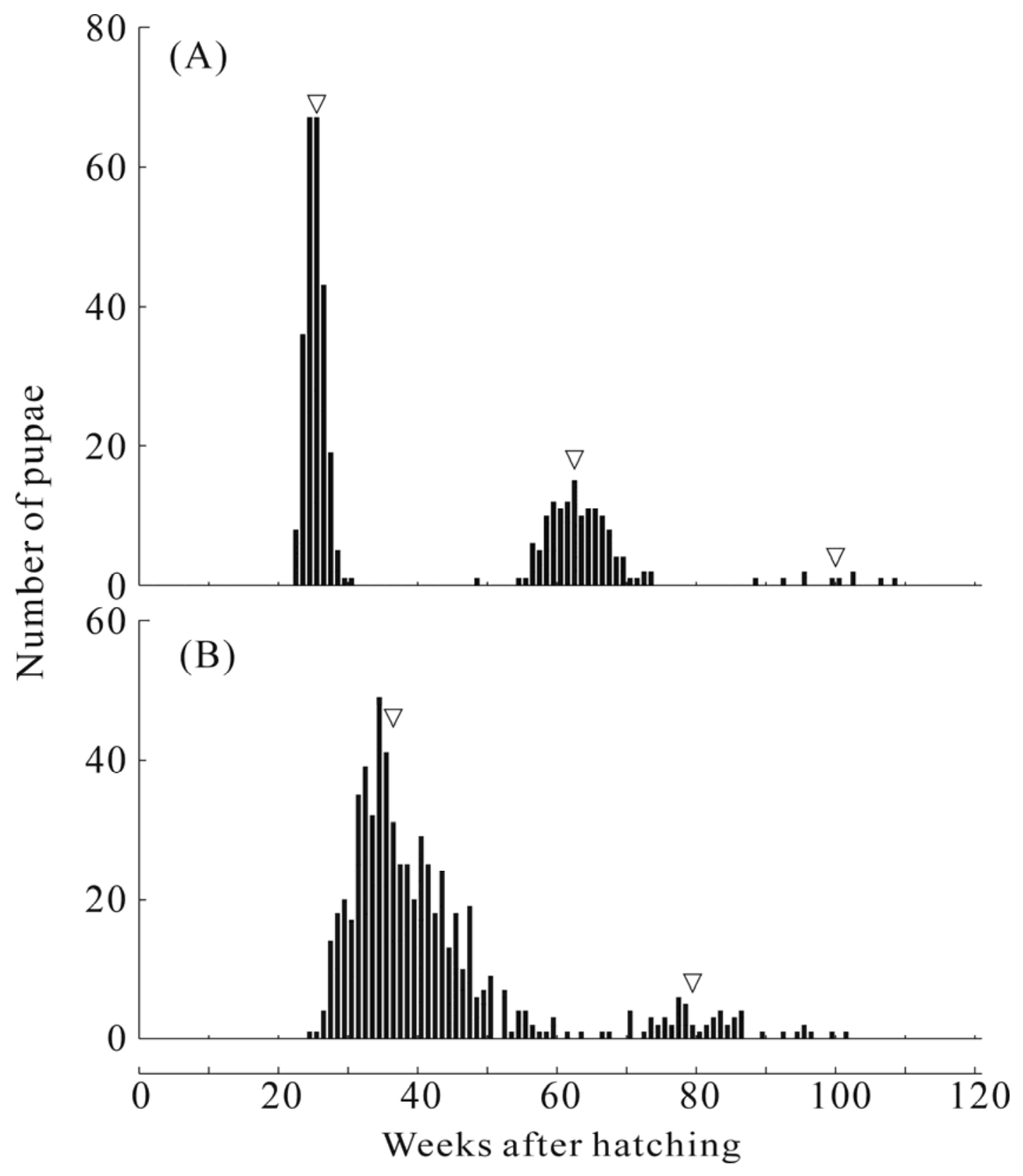

Fig. 1. Pupation of Anthrenus verbasci under LD 12:12 (A) or constant dim light of 0.006 $\mathrm{Wm}^{-2}$ intensity (B) at $20^{\circ} \mathrm{C}$. The triangle indicates the median of each pupation group. Modified from Nisimura and Numata, 2001. 


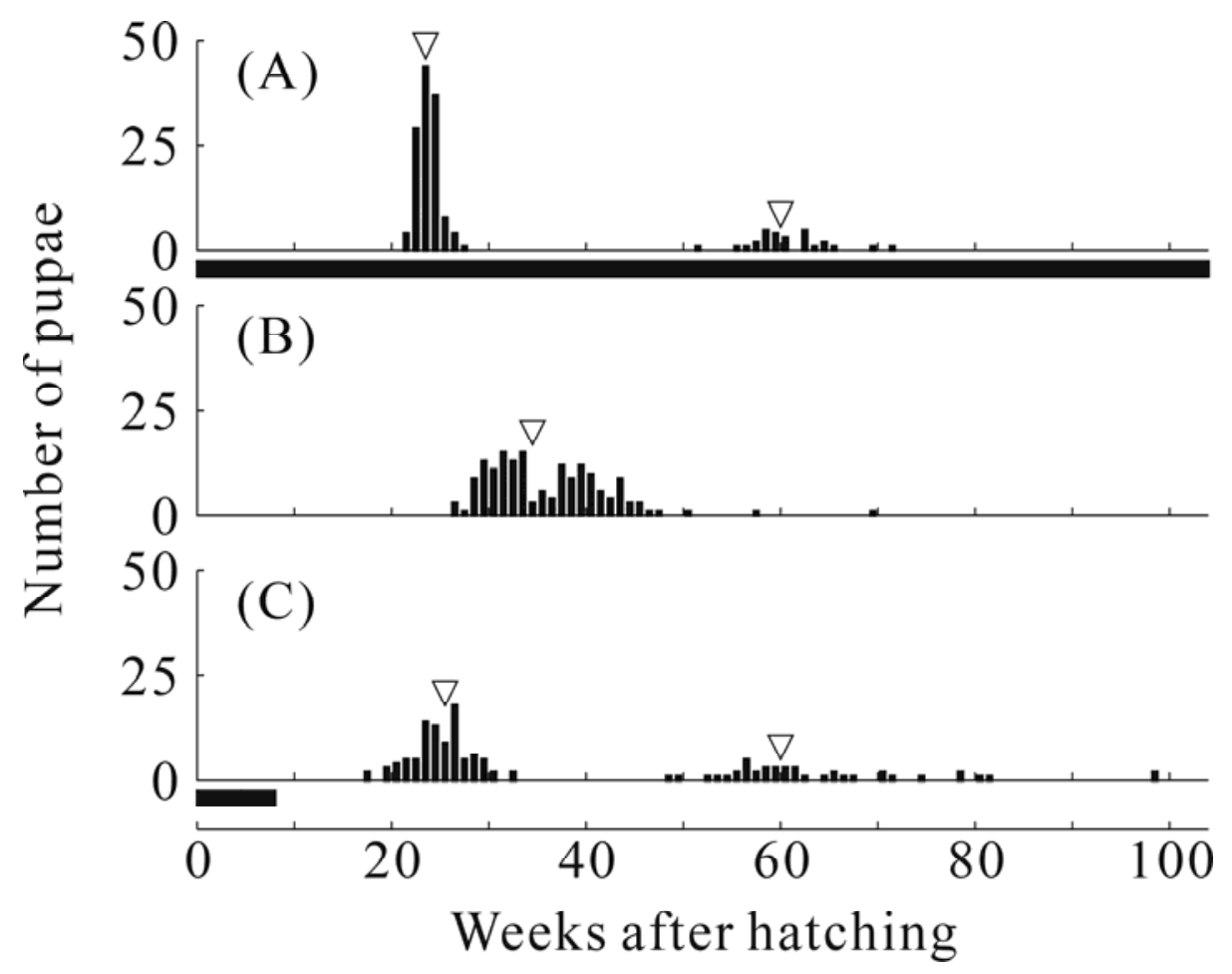

Fig. 2. The effect of pre-exposure to LD 12:12 on pupation of Anthrenus verbasci under constant light of $0.9 \mathrm{Wm}^{-2}$ intensity at $20^{\circ} \mathrm{C}$. Larvae were maintained continuously under LD 12:12 (A) or constant light (B), or transferred from LD 12:12 to constant light at 8 weeks after hatching (C). Filled bars indicate the duration of LD 12:12 exposure. The triangle indicates the median of each pupation group. Modified from Miyazaki and Numata, 2010. 


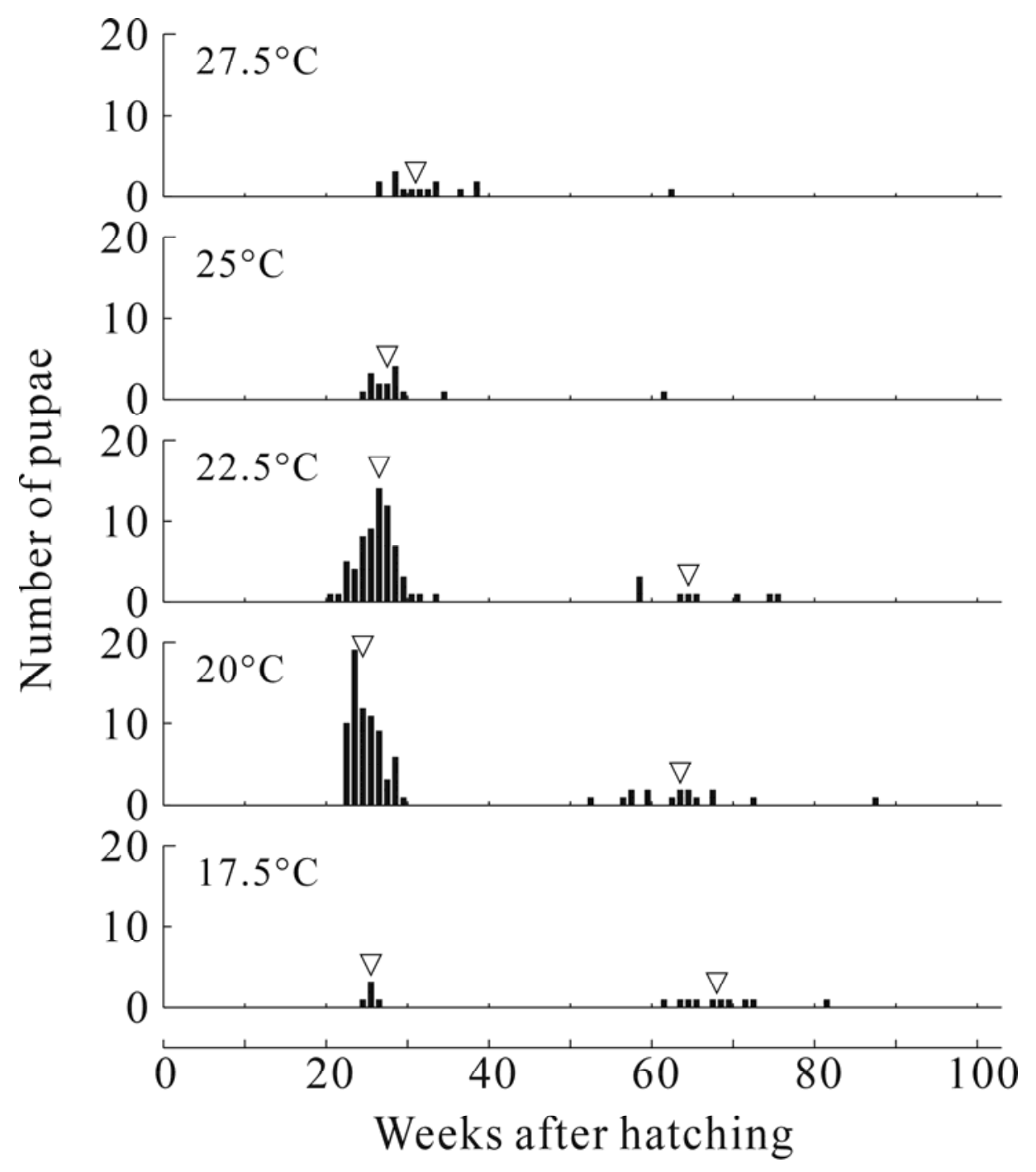

Fig. 3. Pupation of Anthrenus verbasci under LD 12:12 at various constant temperatures. The triangle indicates the median of each pupation group. Modified from Nisimura and Numata, 2001. 


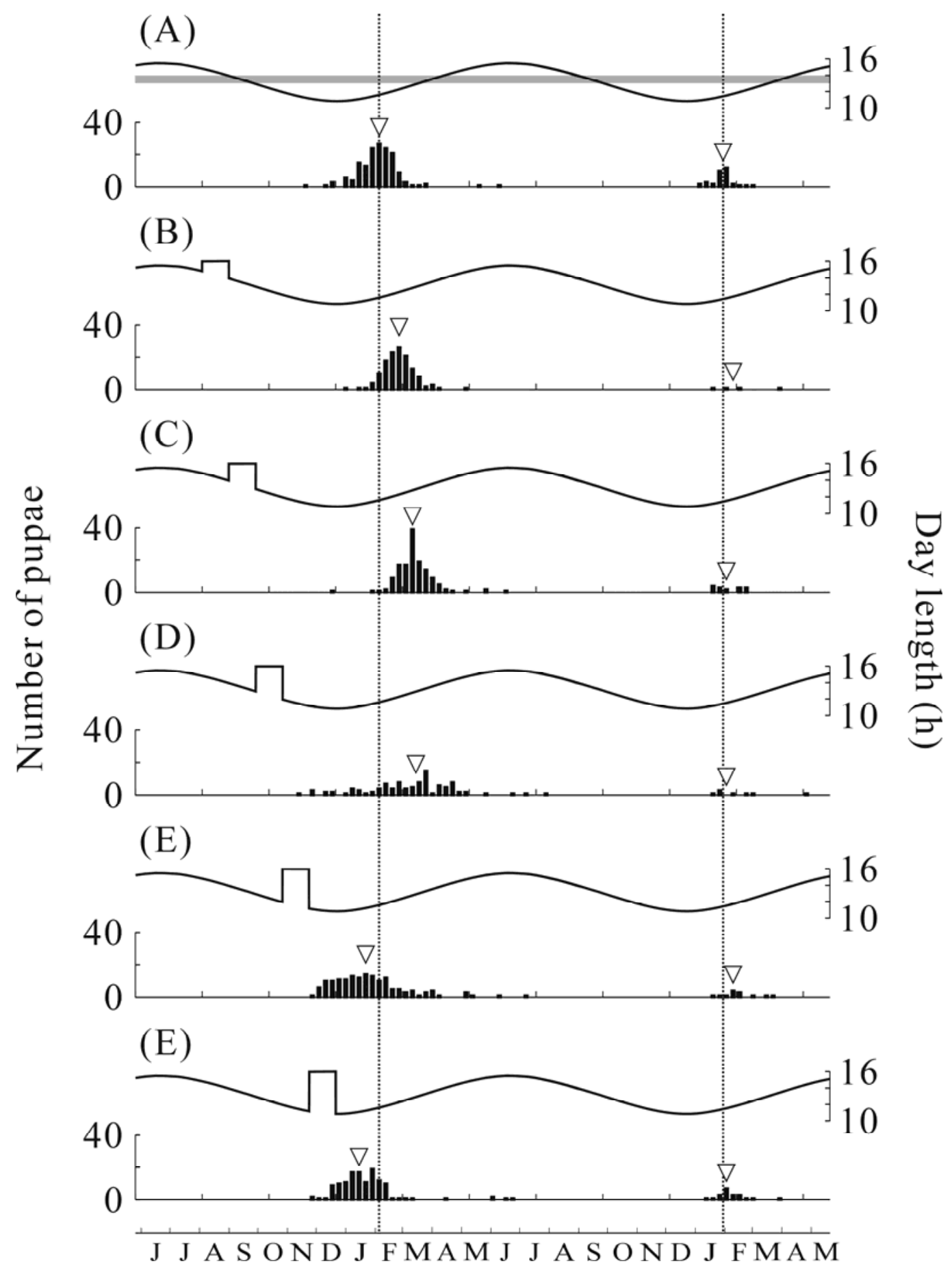

Fig. 4. The effect of a 4-week long-day pulse on pupation of Anthrenus verbasci under naturally changing daylength at $20^{\circ} \mathrm{C}$. Larvae maintained under naturally changing day length were exposed to LD 16:8 for 4 weeks starting on 4 August (B), 1 September (C), 29 September (D), 27 October (E), or 24 November (F). Non-exposed control larvae are shown in (A). The triangle indicates the median of each pupation group. A vertical dotted line crosses through the median of each pupation group in the control experiment (A). The solid curve in each panel indicates the natural day length, including $1 \mathrm{~h}$ of twilight in Osaka, Japan $\left(35^{\circ} \mathrm{N}\right)$ for most of the experiment, and the artificial day length produced by white fluorescent 
lamps during the LD 16:8 pulse. The shaded bar in (A) shows the critical photoperiodic range for determining whether the day length is long or short. Modified from Miyazaki et al., 2006. 


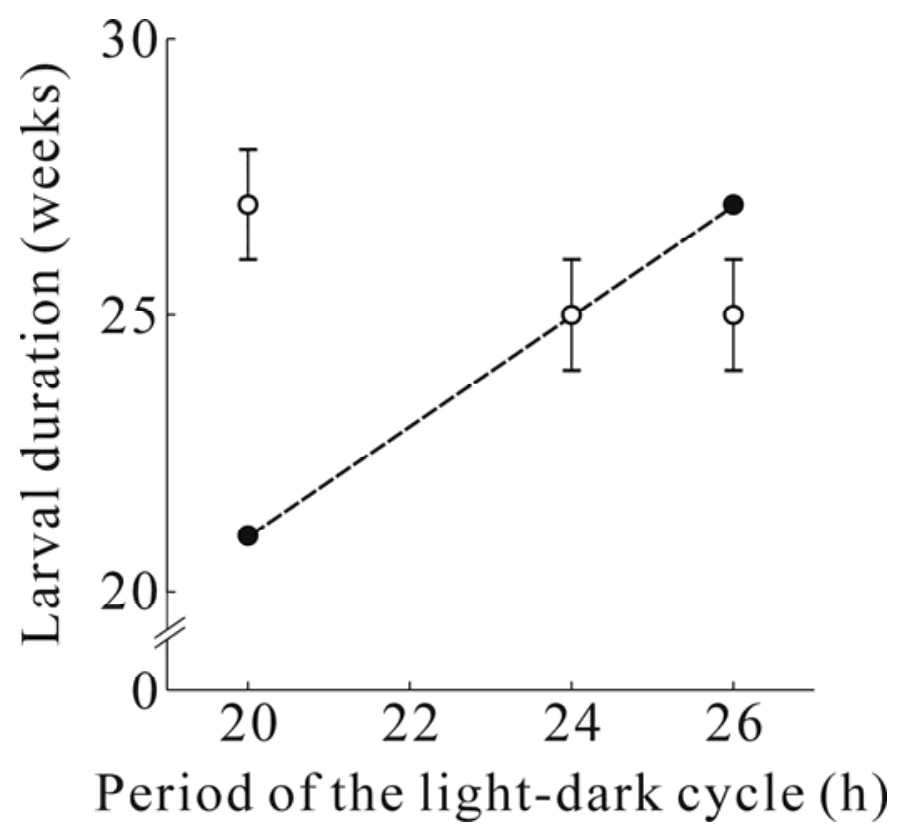

Fig. 5. Evaluation of the frequency de-multiplication hypothesis for the circannual pupation rhythm in Anthrenus verbasci. Larvae were kept under LD 10:10 $(\mathrm{T}=20)$, 10:14 $(\mathrm{T}=24)$, and 10:16 $(\mathrm{T}=26)$ at $20^{\circ} \mathrm{C}$. Open circles represent medians of the first pupation group. Bars represent interquartiles. Closed circles and a broken line represent the timing of the first pupation group predicted by the frequency de-multiplication hypothesis and the results under LD 10:14. Based on the data of Nisimura and Numata, 2002. 


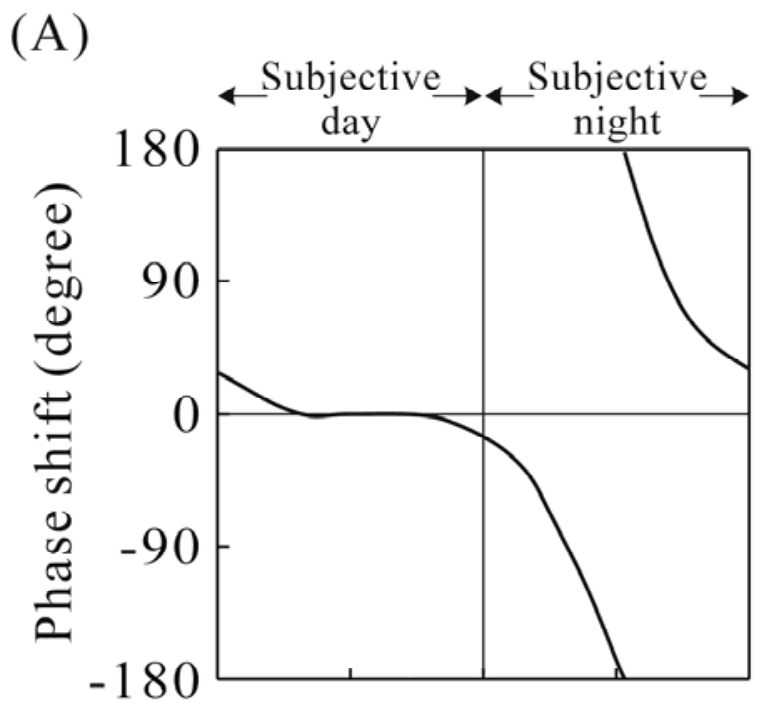

(B)

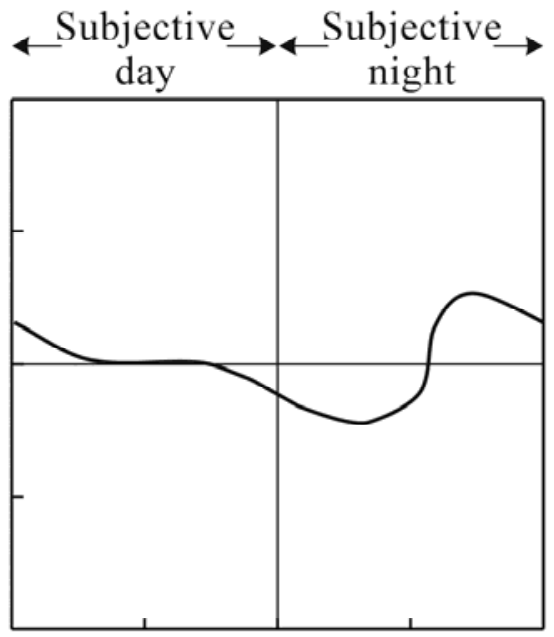

(C)

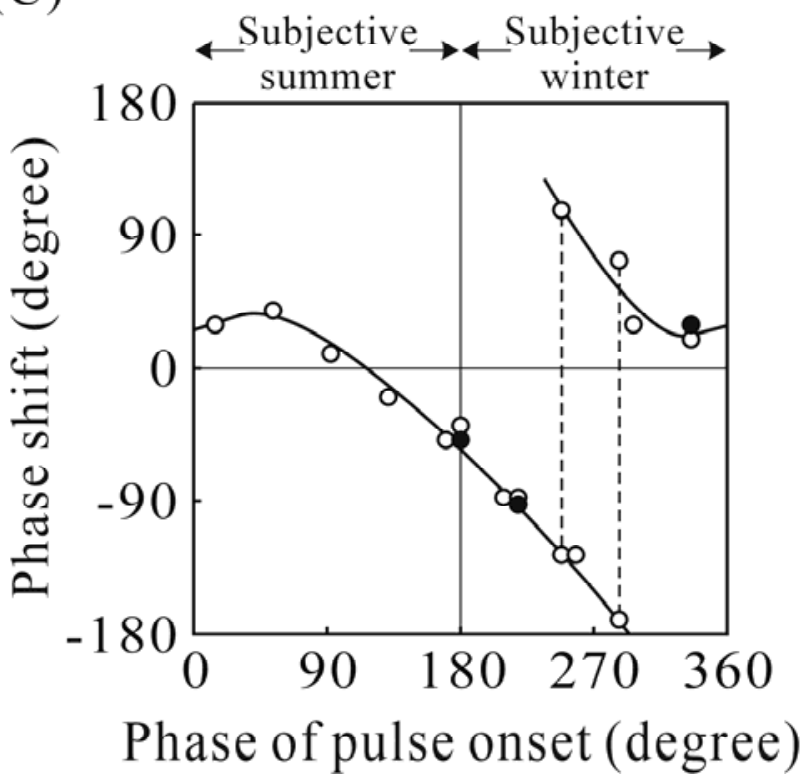

(D)

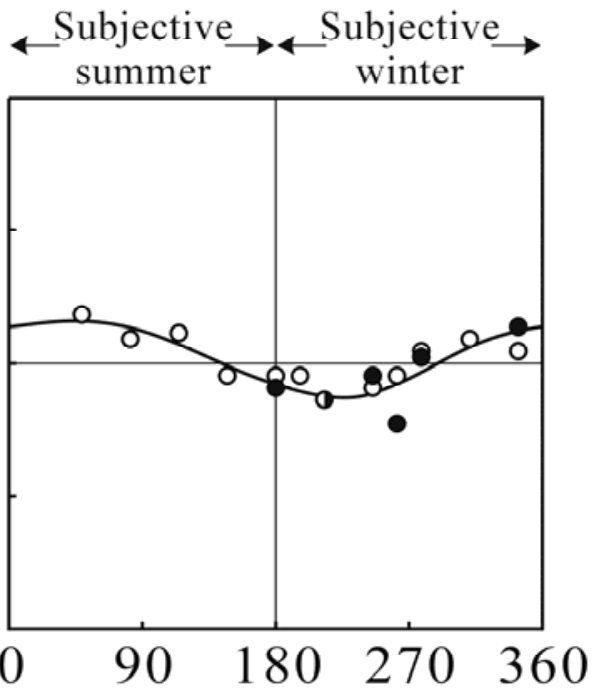

Phase of pulse onset (degree)

Fig. 6. Comparison of phase response curves for circadian and circannual rhythms. (A, B) Phase response curves in circadian rhythms, Type 0 (A) and Type 1 (B). (C, D) Phase response curves in the circannual pupation rhythm of Anthrenus verbasci, a curve to 4-week long-day pulses (C) and a curve to 2-week long-day pulses (D). Larvae were kept under LD $12: 12$ at $20^{\circ} \mathrm{C}$ and exposed to LD $16: 8$ for 4 (C) or 2 (D) weeks at various phases in the circannual rhythm. The circannual period under continuous LD 12:12 is shown in terms of angle degrees $\left(0-360^{\circ}\right)$. Open and closed circles represent the phase shifts in the first and second pupation group after pulse perturbation, respectively. Broken lines in (C) show the split into advanced and delayed groups. (C) from Miyazaki et al., 2005; (D) from Miyazaki et al., 2007. 


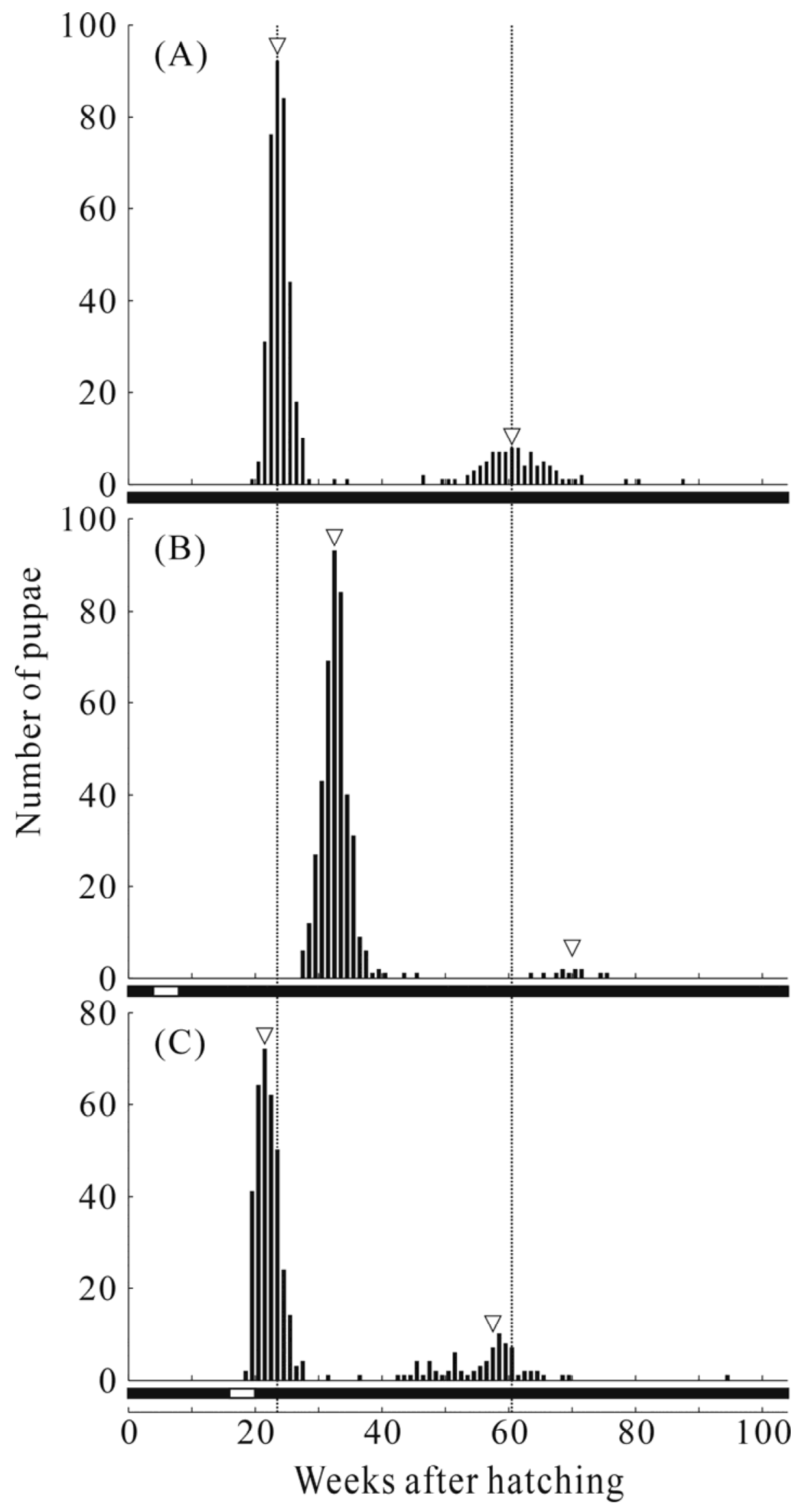


Fig. 7. The effect of a 4-week long-day pulse on pupation of Anthrenus verbasci under LD $12: 12$ at $20^{\circ} \mathrm{C}$. Larvae maintained under LD 12:12 (filled bars) were exposed to LD 16:8 (empty bars) for 4 weeks, commencing 4 weeks after hatching (B) or 16 weeks after hatching (C). Non-exposed control larvae are shown in (A). The triangle indicates the median of each pupation group. A vertical dotted line crosses through the median of each pupation group in the control experiment (A). Modified from Miyazaki et al., 2005. 


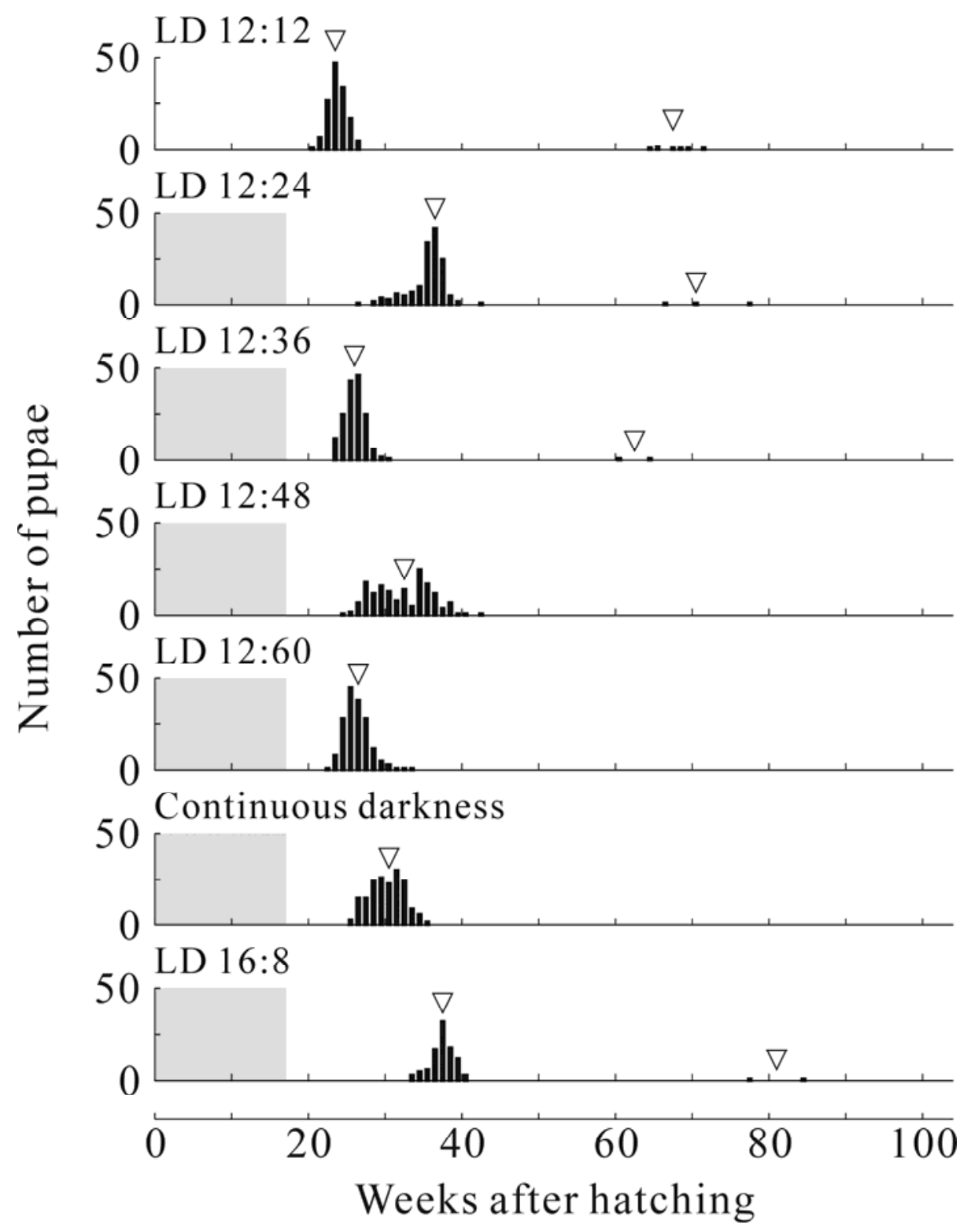

Fig. 8. The effect of exposure to the Nanda-Hamner protocol for 120 days on pupation of Anthrenus verbasci at $20^{\circ} \mathrm{C}$. Larvae were transferred to LD 12:12 after exposure to various photoperiods. Shaded areas represent exposure to various photoperiods. The triangle indicates the median of each pupation group. Modified from Miyazaki et al., 2009b. 


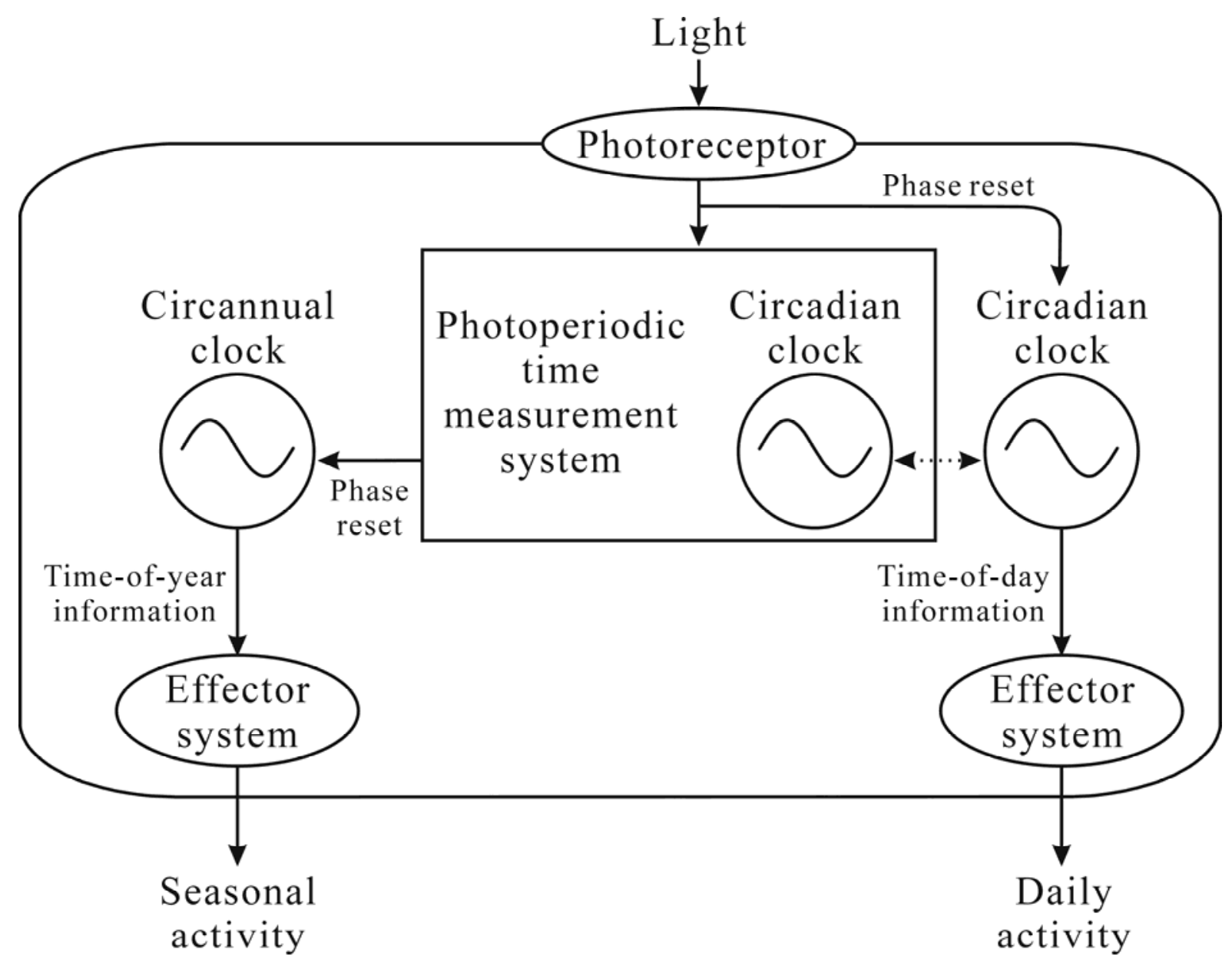

Fig. 9. Schematic diagram of the physiological components of the circannual rhythm in Anthrenus verbasci. The relationship between the circadian clock involved in photoperiodic time measurement and a circadian clock controlling daily activities (dashed arrow) is unclear. 